\title{
Aging Behaviour of Dodecylbenzene in the presence of Copper and Dibenzyl Disulfide (DBDS)
}

\author{
Ian. L. Hosier, Linxu Lai and Alun S. Vaughan, \\ Tony Davis High Voltage Laboratory, \\ University of Southampton, \\ Highfield, \\ Southampton, SO17 1BJ, UK \\ E-mail: ILH@ecs.soton.ac.uk
}

\begin{abstract}
Copper sulfide deposition remains a serious issue in high voltage power transformers and can result in equipment failure. In order to understand the chemistry of this process, dodecylbenzene was used as a model oil system. Copper and dibenzyl disulfide (DBDS) were added in controlled amounts and accelerated aging was then performed. It was found that copper sulfide $\left(\mathrm{Cu}_{\mathrm{x}} \mathrm{S}\right)$ could be formed (i.e. the included copper sheets were blackened) even under non-oxidative conditions but only when DBDS was present in the oil. The reaction was accelerated in the presence of oxygen and competes for available copper with the parallel copper carboxylate producing reaction. The AC breakdown strength was reduced after aging, but exhibited a more catastrophic reduction in oils containing DBDS, confirming the detrimental effects of $\mathrm{Cu}_{\mathrm{x}} \mathrm{S}$ on breakdown performance.
\end{abstract}

Keywords-Dodecylbenzene; Aging; Dibenzyl disulfide; Copper sulfide corrosion; UV/Vis spectroscopy; AC breakdown strength

\section{INTRODUCTION}

Mineral oils are used widely in high voltage transformers and represent a convenient medium for sampling to undertake routine condition monitoring. Despite recent advances in the petrochemical industry, there remains within such oils a significant dissolved sulfur content. This is capable, under operating conditions, of reacting with copper to produce copper sulfide $\left(\mathrm{Cu}_{\mathrm{x}} \mathrm{S}\right)$ deposition on the paper insulation layers within the transformer [1, 2]. This process can lead to disruption of the insulation and therefore to eventual, sometimes catastrophic, failure of the transformer. Replacement of the oil within the transformer does not generally provide a solution due to its high cost, and therefore mitigation strategies, such as passivation and reclamation, were suggested by CIGRE (International Council on Large Electric Systems) [3]. Given the obvious catastrophic potential of copper sulfide deposition it is important to understand the underlying chemistry if effective mitigation methods are to be found.

Many articles [1-8] have discussed the mechanisms of copper sulfide formation including the role of oxygen [2, 4]. Although copper is corroded in sulfurous acidic environments to leave $\mathrm{Cu}_{\mathrm{x}} \mathrm{S}$ [1], dibenzyl disulfide (DBDS) is considered to be the major cause of $\mathrm{Cu}_{\mathrm{x}} \mathrm{S}$ deposition in transformers [2, 3]; consequently it is widely used to simulate a corrosive environment in a non-corrosive oil. Several reaction schemes for the formation of $\mathrm{Cu}_{\mathrm{x}} \mathrm{S}$ have been proposed; for example one scheme envisages $[4,5]$ that insoluble DBDS-Cu compounds are formed within the oil which are then free to migrate to the paper layers where further oxidation converts them to $\mathrm{Cu}_{\mathrm{x}} \mathrm{S}$. Elsewhere [2] two parallel reaction schemes were proposed in order to better explain the observation that $\mathrm{Cu}_{\mathrm{x}} \mathrm{S}$ is found deep within the paper layers of failed transformers. The first (rapid) reaction involves DBDS attacking directly the copper surface to create a film of $\mathrm{Cu}_{\mathrm{x}} \mathrm{S}$, this then migrates through the oil and collects on the surface of the paper layers. The second (slower) reaction occurs mostly within the oil - DBDS is able to attack the copper resulting in soluble organic complexes containing $\mathrm{Cu}$ and $\mathrm{S}$ that are then able to migrate deep into the paper layers where they recombine to give $\mathrm{Cu}_{\mathrm{x}} \mathrm{S}$. Although the chemistry of $\mathrm{Cu}_{\mathrm{x}} \mathrm{S}$ formation is still poorly understood, metal passivators, which serve to provide a barrier to copper corrosion, are highly successful at preventing $\mathrm{Cu}_{\mathrm{x}} \mathrm{S}$ formation $[6,7]$ and are widely employed in plant [3].

The aging behavior of several kinds of insulation oils such as mineral oil [8] and dodecylbenzene [9-11] have been studied extensively. In the simplest system of single isomer DDB [10] the oil is oxidized to produce aromatic ketones which are further oxidized to form carboxylic acids. This then reacts with any available copper to form copper carboxylates. Since acidic environments are known to accelerate the production of DBDS-Cu complexes [2, 4-6], it is expected that adding DBDS may suppress the production of copper carboxylates and thus this could be used as a useful indicator. In this investigation, controlled amounts of dibenzyl disulfide (DBDS) and copper were introduced into dodecylbenzene. These were then aged at high temperatures under both non-oxidative and oxidative conditions. The resulting aging behavior was then studied by $\mathrm{UV} / \mathrm{V}$ is spectroscopy and electrical breakdown testing.

\section{EXPERIMENTAL}

Dodecylbenzene oil samples $(35 \mathrm{ml})$ were placed in $50 \mathrm{ml}$ tall glass vials for aging; these were covered with a Petrie dish to prevent excessive evaporation. Dibenzyl disulfide (DBDS, Sigma Aldrich $98 \%$ ) was added to selected oils at a fixed $2000 \mathrm{ppm}(0.07 \mathrm{~g})$ concentration [2] and samples were stirred for $24 \mathrm{~h}$ using a magnetic stirrer/hotplate to ensure complete dissolution. Copper sheet $(0.1 \mathrm{~mm}$ in thickness $)$ was polished with abrasive paper to remove the surface oxide layer and was then washed with acetone before being placed directly into the oil (total surface area $22.4 \mathrm{~cm}^{2}$ ) [5, 9-11]). All oils were then aged at $135^{\circ} \mathrm{C}$ for 72,168 and $336 \mathrm{~h}[2,4-6,9]$ in three sets as 
follows; set 1 included DBDS and was aged under nitrogen at atmospheric pressure using a vacuum oven, set 2 also included DBDS and was aged under air in a fan oven and set 3 was aged in air but did not contain any DBDS. In addition two unaged reference samples (one with and one without DBDS) were also characterized.

Ultraviolet/visible (UV/Vis) spectroscopy was performed on centrifuged samples (4000 RPM, $10 \mathrm{~min}$ ) except where indicated otherwise. A Perkin Elmer Lambda 35 spectrometer was used with $10 \mathrm{ml}$ PMMA cuvettes (path length $10 \mathrm{~mm}$ ) and scans were performed over a wavelength range of 300 to 1100 $\mathrm{nm}$. Electrical breakdown measurements were performed on homogenized oils using a system built in house incorporating a TTi TG330 function generator, power amplifier, high voltage transformer $(25 \mathrm{kV}$ maximum, $2 \mathrm{~mA})$ and a current trip. The test cell used was a small volume $(8 \mathrm{ml})$ Perspex cylinder containing opposing $25 \mathrm{~mm}$ diameter chrome steel ball bearings with an electrode separation of $1 \mathrm{~mm}$. The applied $50 \mathrm{~Hz}$ AC voltage was increased at a rate of $50 \mathrm{~V} / \mathrm{s}$ and the voltage at breakdown was then noted. The oil was changed after each test and the ball bearings after every 5 tests to reduce the effects of pitting. Tests were performed after allowing the oil to settle for $\sim 2$ min to eliminate air bubbles.

\section{RESULTS AND DISCUSSION}

\section{A. UV/Vis spectroscopy}

Fig. 1 shows UV/Vis spectra from oils set 1, the absorption edge shifts to longer wavelengths as aging progresses (arrowed). There was no evidence of absorption at $680 \mathrm{~nm}$ (copper carboxylates [8-10]) or of precipitate production, although it was observed that the copper sheets included in these samples were blackened. Whilst similar spectra were obtained from DDB aged in an inert atmosphere with copper in isolation [11], the copper sheet was never blackened. Thus the blackening observed here is evidence of $\mathrm{Cu}_{\mathrm{x}} \mathrm{S}$ production and copper corrosion according to the ASTM D130 color table [2], which can occur even under these non-oxidative conditions.

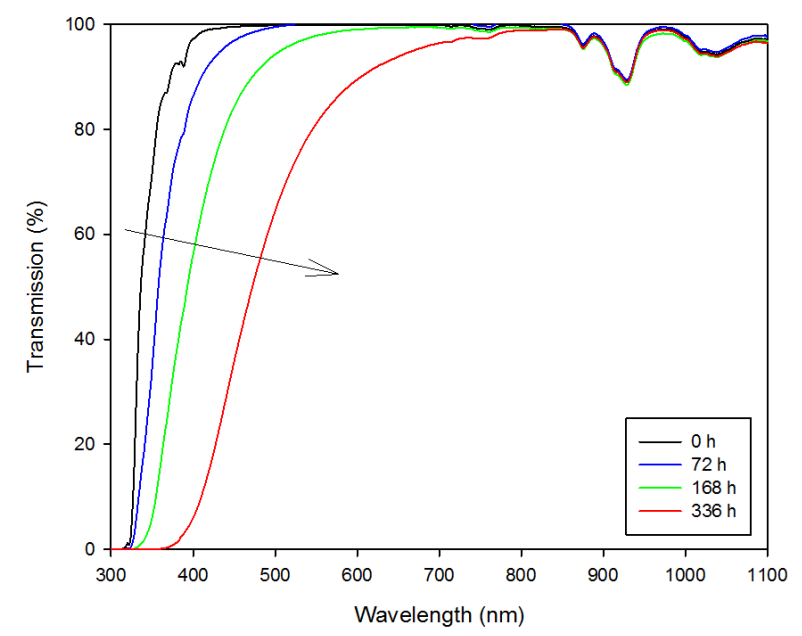

Fig. 1. UV/Vis spectra obtained from oils set 1 (aged under nitrogen with copper and DBDS)
Fig. 2a contains UV/Vis spectra from oils sets 2 and 3; these contained appreciable precipitate and were therefore centrifuged before analysis. The plot serves to illustrate the effect of DBDS inclusion; as expected under these oxidative conditions [9, 10], copper carboxylates are produced (as evinced by absorption at $680 \mathrm{~nm}$ ) followed by precipitate generation. After $72 \mathrm{~h}$ copper carboxylates are evident in set 3 but not in set 2, copper carboxylates are only evident in set 2 after $168 \mathrm{~h}$. Further aging then results in increasing amounts of precipitate. Thus the presence of DBDS is clearly delaying the production of copper carboxylates in the oil as expected.

To quantify the extent of precipitate production both sets of oils were homogenized and the absorbance at $1100 \mathrm{~nm}$ was then measured. The data shown in Fig. $2 b$ confirm higher levels of precipitate production in the presence of DBDS.

\section{B. Examination of copper sheets}

Fig. 3 shows a photograph of the copper sheets removed from sets 1 to 3 (vertical) against aging time in days (horizontal). In addition, Table I provides measurements of the
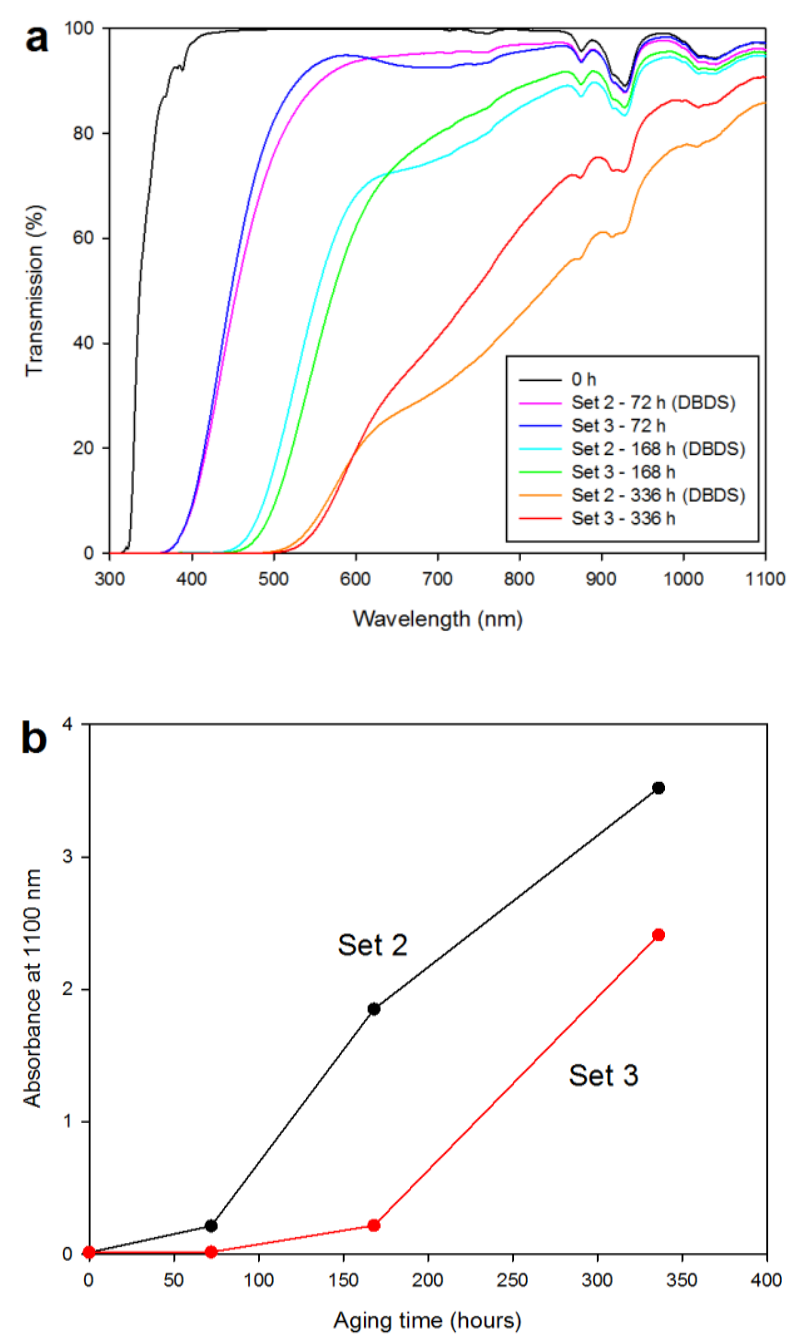

Fig. 2. UV/Vis results; (a) spectra from centrifuged oils sets 2 and 3 (aged under air with copper with and without DBDS) (b) absorbance at $1100 \mathrm{~nm}$ obtained from the same homogenized oils 

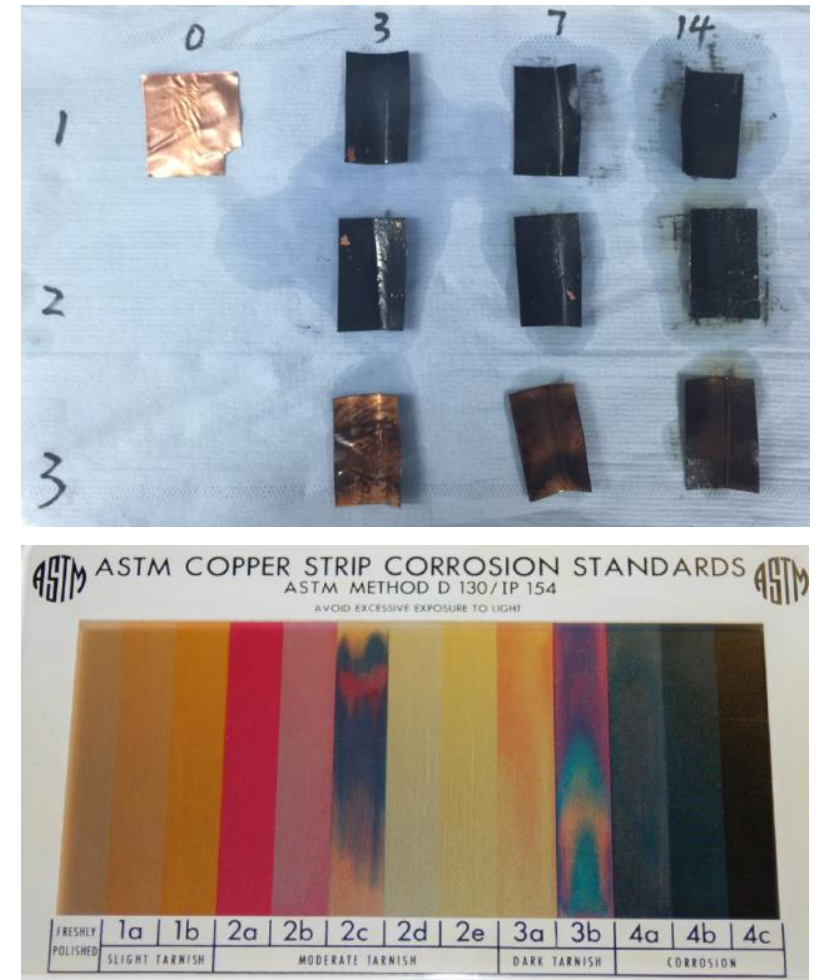

Fig. 3. Copper strips obtained from oils sets 1 through 3 (vertical) against aging time in days (horizontal), ASTM D130 corrosion test chart [2].

TABLE I. MEASURED THICKNESS OF COPPER SHEETS

\begin{tabular}{|c|c|c|c|}
\hline \multirow{2}{*}{$\begin{array}{c}\text { Aging } \\
\text { time }\end{array}$} & \multicolumn{3}{|c|}{ Measured thickness $(\boldsymbol{\mu m})$} \\
\cline { 2 - 4 } & Set 1 & Set 2 & Set 3 \\
\hline $0 \mathrm{~h}$ & $110 \pm 5$ & $110 \pm 5$ & $110 \pm 5$ \\
\hline $72 \mathrm{~h}$ & $104 \pm 3$ & $118 \pm 3$ & $110 \pm 5$ \\
\hline $168 \mathrm{~h}$ & $115 \pm 5$ & $150 \pm 10$ & $105 \pm 5$ \\
\hline $336 \mathrm{~h}$ & $135 \pm 5$ & $200 \pm 20$ & $110 \pm 5$ \\
\hline
\end{tabular}

overall thickness of the copper sheets (measured at 4 separate locations). The copper strip was noticeably blackened in sets 1 and 2 (i.e. with DBDS present) indicating copper corrosion [2]. Layer thicknesses of $\sim 45 \mu \mathrm{m}$ and $\sim 12 \mu \mathrm{m}$ were obtained after aging for $336 \mathrm{~h}$ in air and nitrogen respectively (Table I) indicating that the inert atmosphere significantly reduces the $\mathrm{Cu}_{\mathrm{x}} \mathrm{S}$ production as expected [2, 4, 6]. In contrast the copper sheet is only a little tarnished in set 3 with no measureable increase in thickness (i.e. with no DBDS present). Thus the production of copper sulfides does not require an oxidizing atmosphere or the presence of copper carboxylates.

\section{AC breakdown strength}

Fig. 4 shows Weibull plots and Table II data obtained from breakdown testing. Oils set 1 (Fig. 4a) show a gradual fall in breakdown strength from $15 \mathrm{kV} / \mathrm{mm}$ to $9 \mathrm{kV} / \mathrm{mm}$ (Table II). Fig. $4 \mathrm{~b}$ shows the effects of DBDS inclusion; adding DBDS (set 2) results in a more dramatic fall in breakdown strength than in set 3. Thus oxidative aging with DBDS (where the production of $\mathrm{Cu}_{\mathrm{x}} \mathrm{S}$ is maximized) is clearly having a catastrophic effect on the breakdown strength.
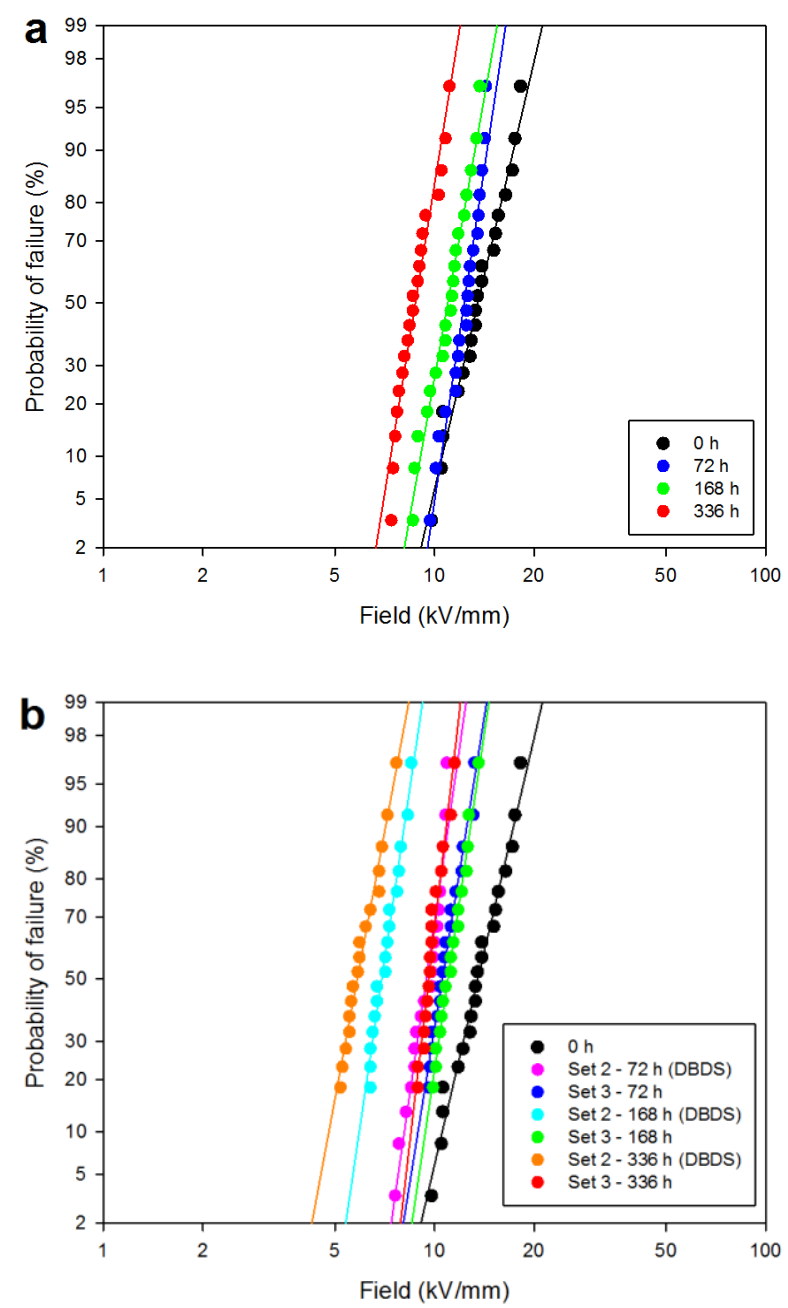

Fig. 4. Weibull plots from aged oils (a) set 1 (aged under nitrogen with copper and DBDS), (b) sets 2 and 3 (aged under air with copper with and without DBDS)

TABLE II. RESULTS FROM AC BREAKDOWN TESTING

\begin{tabular}{|c|c|c|c|}
\hline \multirow{2}{*}{$\begin{array}{c}\text { Aging } \\
\text { time }\end{array}$} & \multicolumn{3}{|c|}{ Breakdown strength in $\mathbf{~ k V} / \mathbf{m m}(\boldsymbol{\beta}$ in parenthesis $)$} \\
\cline { 2 - 4 } & Set 1 & Set 2 & Set 3 \\
\hline $0 \mathrm{~h}$ & $14.8 \pm 1.0(6.3)$ & $14.8 \pm 1.0(6.3)$ & $15.6 \pm 0.7(9.2)$ \\
\hline $72 \mathrm{~h}$ & $13.0 \pm 0.5(11.3)$ & $9.9 \pm 0.4(11.8)$ & $11.3 \pm 0.5(9.1)$ \\
\hline $168 \mathrm{~h}$ & $11.7 \pm 0.6(8.5)$ & $7.4 \pm 0.3(10.2)$ & $11.7 \pm 0.5(10.2)$ \\
\hline $336 \mathrm{~h}$ & $9.3 \pm 0.5(8.1)$ & $6.3 \pm 0.4(7.5)$ & $10.0 \pm 0.4(11.6)$ \\
\hline
\end{tabular}

\section{Reaction of DBDS with copper carboxylates}

It is clear from the above data that formation of copper carboxylates and copper sulfide are competing reactions. In order to determine whether copper carboxylates can be converted into $\mathrm{Cu}_{\mathrm{x}} \mathrm{S}, 200 \mathrm{ml}$ of DDB was aged at $135{ }^{\circ} \mathrm{C}$ for $336 \mathrm{~h}$ without copper. Polished copper sheet $\left(350 \mathrm{~cm}^{2}\right)$ was then added and after 2 weeks the oil had developed a green hue whilst after 8 weeks a deep green color was obtained due to copper carboxylates - absorbance at $680 \mathrm{~nm}$ (Fig. 5). 

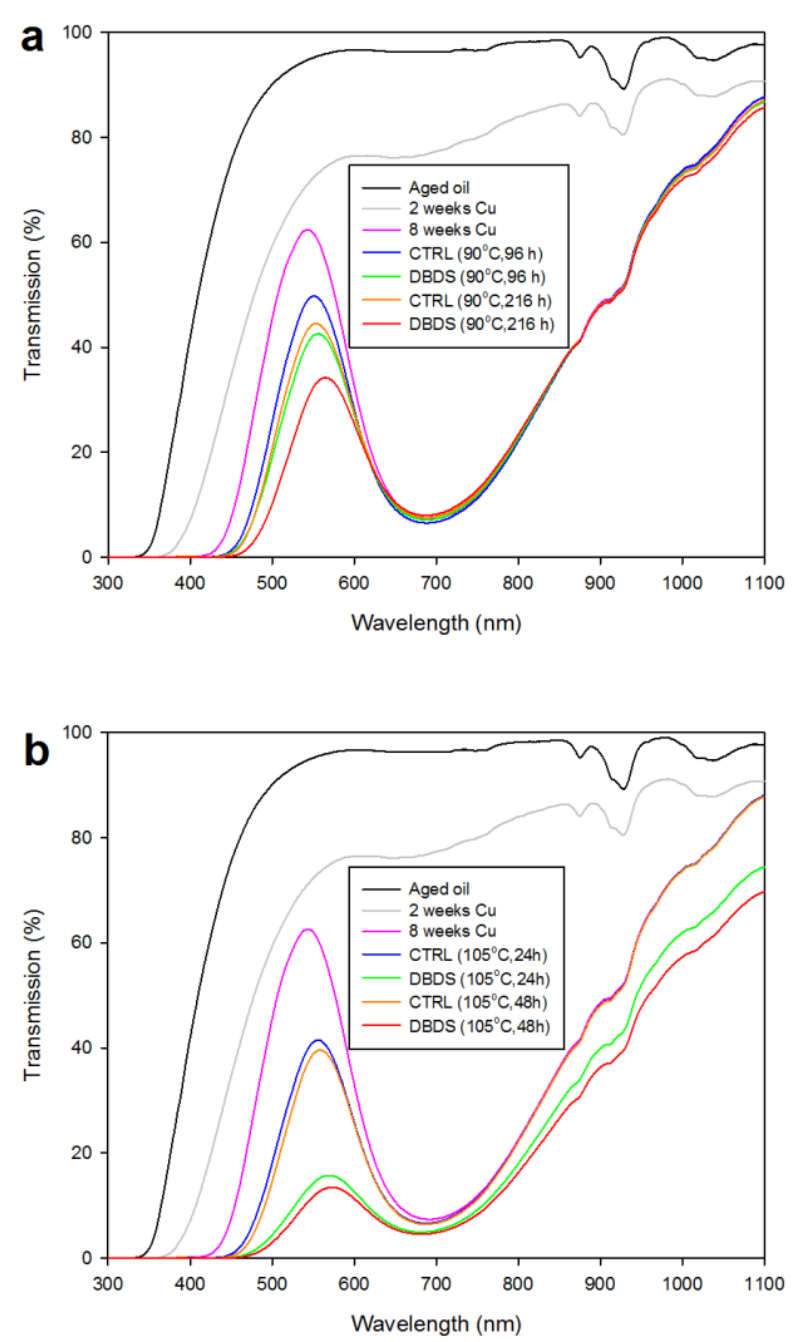

Fig. 5. UV/Vis spectra showing $680 \mathrm{~nm}$ absorbance increasing in intensity as aged oil is exposed to copper. Subsequent samples without (CTRL) and with DBDS (DBDS) were then heat treated at (a) $90{ }^{\circ} \mathrm{C}$ and (b) $105^{\circ} \mathrm{C}$. .

Eight $20 \mathrm{ml}$ samples were then extracted and to four was added an excess of DBDS (5000 ppm, $0.1 \mathrm{~g}$ ) which was stirred in for $24 \mathrm{~h}$. Samples were then heat treated at $90{ }^{\circ} \mathrm{C}$ and 105 ${ }^{\circ} \mathrm{C}$; the resulting spectra (Fig. 5) indicate that the heat treatment causes additional aging of the oil (increasing absorbance at $\sim 540 \mathrm{~nm}$ ) but little change in the copper carboxylate concentration in the absence of DBDS. With DBDS present copper carboxylates are consumed (most evident in Fig. 5a) and are converted into precipitate (i.e. into insoluble $\mathrm{Cu}_{\mathrm{x}} \mathrm{S}$ ), a reaction that is accelerated at the higher temperature (Fig. 5b).

\section{CONLUSIONS}

Oils aged under nitrogen with DBDS and copper were yellowed and the included copper sheet turned black indicating the presence of copper sulfide. Identical aging under air resulted in the formation of copper carboxylates and eventually a precipitate; the copper sheets then showed a greater amount of copper sulfide deposition. Finally, identical aging in air in the absence of DBDS resulted in no copper sulfide and reduced precipitate production compared to aging with DBDS.

With copper and DBDS present, the first appearance of copper carboxylates was delayed compared to the case where only copper was present indicating that both reactions compete for available copper. Copper carboxylates can be readily converted into $\mathrm{Cu}_{\mathrm{x}} \mathrm{S}$ at elevated temperatures.

AC breakdown measurements indicate a reduction in breakdown strength from $15 \mathrm{kV} / \mathrm{mm}$ to $9 \mathrm{kV} / \mathrm{mm}$ following non-oxidative aging in the presence of DBDS (similar to the effects of oxidative aging in the absence of DBDS) but a far more rapid fall to $6 \mathrm{kV} / \mathrm{mm}$ when oxidative aging was undertaken in the presence of DBDS. The $\mathrm{Cu}_{\mathrm{x}} \mathrm{S}$ dissolved within the oil therefore has a catastrophic effect.

\section{REFERENCES}

[1] B. M. Thethwayo, A. M. Garbers-Craig, "Laboratory scale investigation into the corrosion of copper in a sulphur-containing environment", Corros. Sci., Vol. 53, No. 10, pp. 3068-3074, 2011.

[2] M. Facciotti, P. S. Amaro, A. F. Holt, R. C. D. Brown, P. L. Lewin, J. A. Pilgrim, G. Wilson and P. N. Jarman, "Contact-based corrosion mechanism leading to copper sulphide deposition on insulating paper used in oil-immersed electrical power equipment”, Corros. Sci., Vol. 84, pp. 172-179, 2014.

[3] M. Dahlund, I. Atanasova-Höhlein, R. Maina, N. Dominelli, T. Ohnstad, T. Amimoto, C. Claiborne, M.-H. Ese, J. Lukic, V. Mezhvynskiy, Ch. Perrier, P. Smith, J. Tanimura, "CIGRE WG A2-32 Copper sulphide in transformer insulation Final Report", 2009.

[4] H. Kawarai, Y. Fujita, J. Tanimura, S. Toyama, N. Yamada, E. Nagao, N. Hosokawa and T. Amimoto, "Role of dissolved copper and oxygen on copper sulfide generation in insulating oil," Vol. 16, No. 5, pp. 14301435,2009

[5] S. Toyama, J. Tanimura, N. Yamada and E.Nagao, "Highly sensitive detection method of dibenzyl disulfide and the elucidation of mechanism of copper sulfide generation in insulating oil", IEEE Trans. Diel. Electr. Insul., Vol. 16, No. 2, pp. 509-515, 2009.

[6] Y. Liu, L. Yang, E. Hu, J. Huang, "Effect of antioxidants and acids on copper sulfide generation and migration induced by dibenzyl disulfide in oil immersed transformers", IEEJ Trans. Elect. Electr. Eng,, Vol. 10, No. 4, pp. 357-363, 2015.

[7] A. M. Y. Jaber, N. A. Mehanna, G. A. Oweimreen and A. M. Abulkibash, "The Effect of DBDS, DBPC, BTA and DBP combinations on the Corrosion of Copper Immersed in Mineral Transformer Oil", IEEE Trans. Diel. Electr. Insul., Accepted.

[8] I. L. Hosier, S. J.Sutton, A. S. Vaughan and J. Cooper, "An Aging Study of Blends of Dodecylbenzene and Mineral Oil," IEEE Transactions on Dielectrics and Electrical Insulation, Vol.16, No. 6, pp. 1664-1675, 2009.

[9] I. L. Hosier, A. S. Vaughan and F. J. Davis, "Chemical, Physical and Electrical Properties of Aged Dodecylbenzene: Thermal Aging of mixed isomers in air," Dielectrics and Electrical Insulation, IEEE Transactions, Vol. 14, No. 5, pp. 1113-1124, 2007.

[10] I. L. Hosier, A.S.Vaughan, S.J.Sutton and F. J. Davis, "Chemical, Physical and Electrical Properties of Aged Dodecylbenzene 2: Thermal Aging of Single Isomers in Air," Dielectrics and Electrical Insulation, IEEE Transactions, Vol. 15, No. 5, pp. 1393-1405, 2008.

[11] I. L. Hosier, A. S. Vaughan, S. J. Sutton, J. Cooper, F. J. Davis, "Chemical, physical and electrical properties of aged dodecylbenzene 3: Thermal aging of mixed isomers in nitrogen and under sealed conditions", IEEE Trans. Diel. Electr. Insul., Vol. 15, No. 4, pp. 10561064, 2008. 